\title{
Numerical investigation on the ram-scram transition mechanism in a strut-based dual-mode scramjet combustor
}

\author{
Wei Huang ${ }^{*}$, Li Yan ${ }^{\dagger}$ \\ Science and Technology on Scramjet Laboratory, National University of Defense Technology, Changsha, Hunan \\ 410073, People's Republic of China
}

\begin{abstract}
The ramjet and scramjet modes can be realized in the same flowpath using the thermal choking approach, and the dual-mode scramjet combustor has attracted an increasing attention. The ram-to-scram mode transition mechanism in a strut-based dual-mode scramjet combustor has been evaluated numerically, and the
\end{abstract} influences of the inlet boundary conditions at the entrance of the isolator, the injection strategy and the jet-to-crossflow pressure ratio on the mode transition have been investigated. At the same time, the numerical approach has been validated through a turbulent diffusion combustion problem, as well as the effectiveness of the hydrogen-air chemical reaction mechanism. The obtained results show that the inlet boundary conditions at the entrance of the isolator and the jet-to-crossflow pressure ratio both have a large impact on the ram-to-scram mode transition, and the flow upstream of the strut is subsonic when the jet-to-crossflow pressure is large enough, namely 10.0 and 15.0 in the current study. The thermal choking point first appears at the leading edge of the strut, namely nearly at $x=0.25 \mathrm{~m}$. The low freestream Mach number is beneficial for the ramjet mode operation, and the engine would convert into the scramjet mode with the increase of the flight velocity of the vehicle. The influence of the injection strategy employed in this paper can be neglected, and the Mach number distribution upstream of the leading edge of the strut has not been disturbed.

Keywords: Mode transition; dual-mode scramjet combustor; mixing efficiency; Mach number; supersonic flow

\footnotetext{
* Associate Professor, Corresponding author, Email: gladrain2001@163.com, Phone: +86 731 84576447, Fax: +86 73184512301 $\dagger$ Associate Professor, Corresponding author, Email:scarlet@163.com, Phone: +86 731 84576452, Fax: +86 73184512301 


\section{Nomenclature}

$A \quad=$ cross section of the axial station where mixing is evaluated $\left(\mathrm{m}^{2}\right)$ or pre-exponential factor

$C_{\mathrm{p}} \quad=$ specific heat $(\mathrm{J} /(\mathrm{kg} \bullet \mathrm{K}))$

$H \quad$ height $(\mathrm{km})$

$k \quad=$ turbulent kinetic energy $\left(\mathrm{m}^{2} / \mathrm{s}^{2}\right)$

$\mathrm{Ma}=$ Mach number

$M_{\mathrm{i}} \quad=$ Mach number at the entrance of the isolator

$M_{\infty} \quad=$ Mach number for free stream

$\dot{m}_{f u e l, \text { mixed }}=$ mixed injectant mass flow

$\dot{m}_{\text {fuel, total }}=$ total injectant flow rate

$N \quad=$ temperature exponent

$o \quad=$ origin of coordinate system

$P_{\mathrm{i}} \quad=$ total pressure at the entrance of the isolator (atm)

$T_{\mathrm{a}} \quad=$ activation energy $(\mathrm{J} /(\mathrm{kg} \bullet \mathrm{mol}))$

$T_{\mathrm{i}} \quad=$ total temperature at the entrance of the isolator $(\mathrm{K})$

$u \quad=$ local velocity $(\mathrm{m} / \mathrm{s})$

$x \quad=$ horizontal distance $(\mathrm{mm})$

$y \quad=$ vertical distance $(\mathrm{mm})$

$y^{+}=$nondimensional parameter

$\alpha \quad=$ injectant mass fraction

$\alpha_{\text {react }} \quad=$ injectant fraction mixed in a proportion that can react

$\alpha_{\text {stoic }}=$ injectant stoichiometric mass fraction 


$\begin{array}{ll}\rho & =\text { local density }\left(\mathrm{kg} / \mathrm{m}^{3}\right) \\ \eta_{m} & =\text { mixing efficiency } \\ \omega & =\text { specific dissipation rate }\end{array}$

\section{Introduction}

The dual-mode scramjet combustor is the most important component for the combined cycle engine of single-stage-to-orbit transportation systems or hypersonic transportation systems [1], and it attracts an increasing attention worldwide $[2,3]$. As we all know, the engine would own the best performance on the ramjet mode when the flight Mach number ranges from 3.0 to 6.0. However, the performance is the best on the scramjet mode with the flight Mach number being over $6.0[4,5]$. That is to say, the engine should operate on the dual modes, and the ramjet and scramjet modes can be realized using the thermal choking approach.

Cao et al.[6] simulated a scramjet engine with two-staged hydrogen injection from Mach 4 to 7 by one-dimensional numerical method, and three typical combustion modes were attained by changing the total amount of fuel added or adjusting the fuel distribution between two injectors. A scramjet combustor with both single and two-stage fuel injection was examined experimentally by Kobayashi et al. [7] in order to evaluate its operating mode. Zhang et al.[8] investigated the influences of the fuel type, the injector configuration, the inflow total temperature and the fuel injection distribution on the mode transition experimentally, and three combustion modes, namely pure scram mode, dual-mode scram mode and dual-mode ram mode, were classified through the wall pressure distributions, one-dimensional performance analysis and optical visualization. At the same time, they observed hysteresis phenomenon in the mode transition region. Further, Cui et al.[9] developed a mechanical model to investigate the nonlinear behavior of mode transition, and they found that the hysteresis phenomenon originates from the unstable positive feedback mechanism of shock motion, and its topological rule is discovered using Thom's classification theorem. Bao et al.[10] studied the dynamic characteristics of 
combustion mode transition on a liquid-fueled strut-based scramjet combustor experimentally, and three different combustion modes according to the number of thermal choking points were observed and evaluated. At the same time, they found that the hysteresis effect is very important for the control system design of the vehicle. Pressure measurements and high-speed laser interferometry were employed by Fotia and Driscoll [11] to examine the behavior of a ram-to-scram transition, and a regime diagram that represents the parameter space defined by the fuel equivalence ratio and inlet stagnation temperature was obtained. Huang et al. [12] observed the ram-to-scram mode transition induced by the variance of the injection temperature and pressure as well. The first demonstration of mode transition solely induced by the test gas vitiation was conducted experimentally by Goyne et al.[13], and they observed that the fuel equivalence ratio for the transition from supersonic to dual mode is higher for the ground facility tests. Further, Rockwell Jr.[14] evaluated the influence of test-medium vitiation on dual-mode scramjet combustor at Mach 5 enthalpy facility, and the hysteresis phenomenon was observed as well in the dual-mode transition region.

Recently, Turner and Smart [15] investigated the variation in thrust and combustion efficiency of a three-dimensional scramjet engine in different modes experimentally, and they found that small changes in combustor area distribution have important effects on scramjet operability and performance. Two types of combustion mode were identified by Xiao et al. [16] based on the heat release distribution of combustor and flow configuration of isolator. An improved method including finite-rate chemistry and high-temperature gas properties was proposed by Torrez et al. [17] to compute the thrust of a dual-mode scramjet engine, and this method is expanded from the simple Shapiro approach. Further, the predicted results obtained for both ramjet and scramjet modes were validated through comparing with the experimental data, and the benefits of the pseudo-one-dimensional approach were observed.

From the above information, we observe that the experimental test of the dual mode scramjet combustor has been carried out by many scholars, and rare numerical simulation has been conducted, especially on the 
parametric evaluation. Milligan et al.[18] established a baseline numerical approach to evaluate the efforts in a supersonic wind-tunnel facility at U.S. Air Force Research Laboratory (AFRL), and the detailed flow field information were not provided, as well as the information on the mode transition from the simulation aspect. Abdel-Salam and Carson [19] provided a three-dimensional numerical investigation on a dual-mode combustor, and fuel was injected through single unswept ramp. In their study, three kinds of fuel were employed, namely hydrogen, methane and ethylene, but the mode transition mechanism was not considered. The application of the computational fluid dynamics method in the simulation on the reacting flow field of a scramjet combustor would provide new and detailed information on the aspects discussed in the previous paragraphs. Thus, in the current study, the ram-to-scram mode transition mechanism in a strut-based dual mode scramjet combustor has been investigated numerically, and the influences of the inlet boundary conditions at the entrance of the isolator, the injection strategy and the jet-to-crossflow pressure ratio on the mode transition have been evaluated. This information would be beneficial for the flowpath design of the combined cycle engine.

\section{Physical model and numerical method}

\subsection{Physical model}

The geometric model employed in this paper is based on a typical strut-based scramjet combustor, see Fig.1, and a similar model was tested at the German Aerospace Center, Stuttgart [20]. Fig.1 depicts the schematic diagram of the strut-based dual-mode scramjet combustor, and it consists of an isolator, a constant-area combustor and a divergent combustor. The position $x=0$ is at the entrance of the model, see Fig.1. The length and height of the isolator are $200 \mathrm{~mm}$ and $18 \mathrm{~mm}$, respectively. The isolator is used to contain the shock wave train and prevent the interaction between the scramjet combustor and the inlet due to the pressure rise caused by the intense turbulent combustion in the combustor [21]. The isolator ends in a small step both on the top and bottom walls, and the height of the step is $3 \mathrm{~mm}$. Downstream of the step is a constant-area combustor section of 
length $80 \mathrm{~mm}$. From $x=280 \mathrm{~mm}$ on, the upper wall of the combustor diverges with a constant angle of $3^{\circ}$ to compensate for the boundary layer growth, and its length is $300 \mathrm{~mm}$. A strut is placed at the centerline, namely $y$ $=9 \mathrm{~mm}$, and the strut base is located at the entrance of the divergent combustor, namely $x=280 \mathrm{~mm}$. The length of the strut is $32 \mathrm{~mm}$, and its half-angle is $6^{\circ}$. Hydrogen is injected horizontally from the center of the strut base with local sonic velocity $\left(T_{1}\right)$, and it is injected vertically $95 \mathrm{~mm}$ downstream of the entrance of the constant-area combustor as well ( $T_{2}$ and $T_{3}$ ), see Fig. 1 . The width of the injection slot is $0.25 \mathrm{~mm}$. Table. 1 shows the boundary conditions for the cases employed in the current study, and four conditions are chosen for the entrance of the isolator. The total temperature of the injectant is fixed to be $1200 \mathrm{~K}$, and the jet-to-crossflow pressure ratio is varied in order to consider its influence on the mode transition. The jet-to-crossflow pressure ratio is proved to be a critical operating parameter for the mixing augmentation in supersonic flows [22]. In the current study, its value is 3.43, 7.0, 10.0 and 15.0 for Case 1 . In reality, higher jet-to-crossflow pressure ratio means higher equivalence ratio, and this would result in larger heat release. The ram-to-scram mode transition is proved to take place by increasing heat release as well [23], and this is beyond of the scope in this paper, as well as the influence of wall temperature. This topic would be carried out in the near future.

\subsection{Numerical approach}

Numerical simulations are carried out using FLUENT version 6.3.26, and the mesh generation has used the commercial software Gambit [24]. The governing equations are two-dimensional compressible Reynolds-Average Navier-Stokes equations (i.e. the laws of conservation of mass, momentum, and energy). The flow equations are solved with an implicit density based solver. The flow is assumed to be ideal, and the influence of molecular viscosity is assumed negligible. The mass-weighted-mixing-law is used to compute the thermal conductivity and viscosity. An implicit second-order upwinding scheme is used for spatial discretization. The main flow is modeled as air with $21 \% \mathrm{O}_{2}$ and $79 \% \mathrm{~N}_{2}$, and the jet is modeled as hydrogen. Mass weighted 
mixing law is used for viscosity values while the mixing law is used for $C_{\mathrm{p}}$.

The turbulent flowfield region is solved using a semi-empirical model, based on model transport equations for the turbulent kinetic energy $(k)$ and specific dissipation rate $(\omega)$ called shear stress transport (SST) $k$ - $\omega$ with default model constants using second-order upwinding scheme. Here, the turbulent viscosity is modified to account for the transport of the principal turbulent shear stress. Other modifications include the addition of a cross-diffusion term in the $\omega$ equation and a blending function to ensure that the model equations behave appropriately in both the near-wall and far-field zones [25]. The detailed transport equations for $k$ and $\omega$ can refer to Ref. [26]. The turbulence-chemistry interaction is considered using the finite-rate/eddy-dissipation reaction model, and two different $\mathrm{H}_{2}$-air mechanisms are employed in the current study, see Table.2. The seven-step $\mathrm{H}_{2}$-air mechanism was successfully employed to investigate the turbulent diffusion combustion by the authors [28]. The finite-rate/eddy-dissipation reaction model can capture the wave behavior and predict the location of the wave system in the combustion flow field. Table. 2 shows the rate parameters for the different $\mathrm{H}_{2}$-air mechanisms, and the reacting rates are calculated using the Arrhenius equation. The Courant-Friedrichs-Levy (CFL) number remains at 0.5 with suitable under-relaxation factors to ensure stability. Also, a compressibility correction is used to solve the boundary layer region. The flux splitting scheme for convective terms is evaluated by an advection upstream splitting method (AUSM) [29].

The inlet of the main flow, as well as the exit of the wall orifice, is modeled as a pressure inlet condition where the total pressure, static pressure, and total temperature are specified. The outlet is the pressure outlet where the conditions are extrapolated from the interior owing to high supersonic nature of the flow. All the solid surfaces are considered as stationary (no-slip) by setting the velocity components to zero and nullifying the energy contributions of the wall faces to the dissipative fluxes. The computational domain is discretized into multiblocks, see Fig.2, and uniform structured grids are generated to solve the flowfield. Fig.2 represents the close-up view for the grid system around the strut and steps. The grids are generated to capture the entire flow 
physics such as separation shock wave, flowfield immediately downstream the injection, separation point, vortex structure in the boundary layer, and jet interaction effects. The grid density is clustered towards the injection port and the walls of the combustor for all grids and relaxed towards outlet. A boundary layer grid is generated on the bottom wall with a first cell height of $0.01 \mathrm{~mm}$, which results in a suitable value of $y^{+}$for all of the flow fields, namely its maximum value is less than 50 .

\section{Code validation}

In this section, the experimental model, as studied by Marshall and Kurkov [30], is used to provide data for evaluation of the numerical method. The experimental cases of Marshall and Kurkov [30] are of great value because they provide good spatial resolution of the species distribution, and this model can obtain a nearly two-dimensional flow. Fig.3 depicts the hydrogen mole fraction profile comparison at the exit of the combustor under the combustion condition, and it is observed that the predicted results both show reasonable agreement with the experimental data even though the profiles are both under-predicted. This may be induced by the inaccuracy of the turbulence model employed in this paper. At the same time, it is obvious that the $\mathrm{H}_{2}$-air chemical reaction mechanism has only a slight impact on the hydrogen mole distribution, and the seven step mechanism is employed in the following simulation in order to cut the computational cost.

\section{Results and discussion}

\subsection{Effect of inlet boundary condition}

In this part, the boundary conditions at the entrance of the isolator are varied in order to evaluate their influence on the mode transition, see Table.1, and the boundary condition for the jet exit keeps constant. That is to say, the jet-to-crossflow pressure ratio is set to be 3.43 .

Fig.4 shows the Mach number contour comparison for cases with different inlet boundary conditions, and it is 
clearly observed that the separation zone extends into the isolator when the freestream Mach number is lower, see Figs.4 (a) and (b). This implies that the flow field upstream of the leading edge of the strut is influenced by the intensive combustion under these conditions, and the dual-mode combustor would occur in the ramjet mode, see Fig.5. Fig.5 represents the Mach number profile comparison for cases with different inlet boundary conditions, and the Mach number is obtained by the mass-weighted average approach. In Fig.5, it is clearly observed that the subsonic flow occurs for Cases 1 and 2, and the thermal choking takes place. Then, the engine would operate on the ramjet mode. In the ramjet mode operation, the supersonic free stream is decelerated to subsonic in prior to combustion. With heat release, the subsonic flow accelerates to sonic speed, and the pressure decreases with heat addition process. The lowest Mach number is at the leading edge of the strut, namely nearly at $x=0.25 \mathrm{~m}$, and this may be the location of the thermal choking throat. However, when the freestream Mach number is higher, see Figs.4(c) and (d), the low velocity region in the vicinity of the strut base becomes smaller, and the largest separation zones at the top and bottom walls of the flowpath are both located nearly at $x=0.25 \mathrm{~m}$. This is just the location of the strut tip, and that may imply that the thermal choking phenomenon would occur firstly at the strut tip. This conclusion is consistent with that observed in Cases 1 and 2, and it is further illustrated that the boundary conditions at the entrance of the isolator have a great impact on the mode transition for the dual-mode transition.

Further, the mixing efficiency is used to evaluate the influence of the inlet boundary condition on the flow field property of the dual-mode scramjet combustor, and its definition is as follows [31].

$$
\eta_{m}=\frac{\dot{m}_{\text {fuel }, \text { mixed }}}{\dot{m}_{\text {fuel }, \text { total }}}=\frac{\int \alpha_{\text {react }} \rho u d A}{\int \alpha \rho u d A}
$$

Herein,

$$
\alpha_{\text {react }}=\left\{\begin{array}{c}
\alpha, \alpha \leq \alpha_{\text {stoic }} \\
\alpha(1-\alpha) /\left(1-\alpha_{\text {stoic }}\right), \alpha>\alpha_{\text {stoic }}
\end{array}\right.
$$

$\alpha$ is injectant mass fraction, $\alpha_{\text {react }}$ is the injectant fraction mixed in a proportion that can react, $\alpha_{\text {stoic }}$ is the injectant stoichiometric mass fraction, $\dot{m}_{f u e l, \text { mixed }}$ is the mixed injectant mass flow and $\dot{m}_{f u e l, \text { total }}$ is the total 
injectant flow rate. $\rho$ and $u$ are the local density and velocity respectively, and $A$ is the cross section of the axial station where mixing is evaluated.

Fig.6 depicts the mixing efficiency comparison for cases with different inlet boundary conditions, and we observe that the higher freestream Mach number is beneficial for the mixing between the air and hydrogen. The mixing process between the air and hydrogen is carried out completely at $x=0.35 \mathrm{~m}$ for Cases 3 and 4 , and the variable trend of the mixing efficiency profiles for Cases 3 and 4 are the same. That may imply that the mixing efficiency would not vary when the freestream Mach number is large enough for a certain special configuration.

\subsection{Effect of injection scheme}

In this section, the influence of the injection strategy on the mode transition has been evaluated numerically, and the arrangement of the injection scheme in this paper is shown in Table.3. In Case 5, the hydrogen is injected from the base plane of the strut and the bottom wall of the combustor. In Case 6, the hydrogen is injected from the base plane of the strut and the top wall of the combustor. In Case 7, the hydrogen is injected only from the base plane of the strut. The boundary conditions of Cases 5-7 are the same as that of Case 1.

Fig.7 depicts the Mach number contour comparison for cases with different injection schemes, and it is clearly shown that the flow fields are nearly the same, and the injections from the top and bottom walls of the combustor would block the supersonic flow. Accordingly, the flow could not expand to the exit of the combustor sufficiently. We could observe that the Mach number at the exit of the combustor for Case 7 is much larger, and this phenomenon is consistent with the results illustrated in Fig.8. Fig.8 shows the Mach number profile comparison for cases with different injection schemes, and it is observed that the injection strategy employed in the current study could not affect the parametric distribution upstream of the strut. This means that all the cases employed in this part operate in the ramjet mode, and this conclusion is different with that observed in Ref.[32]. This phenomenon depends on the inlet boundary conditions as well. However, the flow field varies with the 
variance of the injection scheme, and the flow expands more sufficiently in Case 7. The Mach number at the exit of the combustor is larger than that at the entrance of the isolator. At the same time, we observe that the mixing process between the air and fuel is carried out more completely in Case 7, see Fig.9, and this implies that the blockage of the supersonic flow induced by the hydrogen injection would not be a beneficial issue for the mixing improvement. This phenomenon is contrary to that observed by Northam and Anderson [33]. In the two-dimensional flow field, the perpendicular jet would block the supersonic air flow to cause low pressure condition at the backward-side of the jet, which in turn, bent the fuel jet toward the wall, resulting in poor penetration and mixing. This negative effect should be avoided in the design of the dual-mode scramjet combustor. However, the phenomena in the three-dimensional real flow field may be different due to the effect of sidewall, and this would be conducted in the near future.

\subsection{Effect of jet-to-crossflow pressure ratio}

In this section, the jet-to-crossflow pressure ratio varies in order to evaluate its effect on the mode transition, and Case 1 is chosen as the benchmark as well. The other jet-to-crossflow pressure ratios are 7.0, 10.0 and 15.0, see Table.4, and Table.4 illustrates the jet-to-crossflow pressure ratios for Cases 8-10.

Fig.10 shows the Mach number contour comparison for cases with different jet-to-crossflow pressure ratios, and it is shown that the separation zone expands upstream with the increase of the jet-to-crossflow pressure ratio, see Fig.10(b). When the jet-to-crossflow pressure is high enough, namely 10.0 and 15.0 in the current study, the shock wave train generated in the isolator would be pushed out of the isolator, and the inlet unstart phenomenon would occur, see Figs.10(c) and (d).This phenomenon occurs in the scramjet combustor with backward-facing steps as well [34]. The engine would operate in the ramjet mode completely with the increase of the jet-to-crossflow pressure ratio, see Fig.11. Fig.11 depicts the Mach number profile comparison for cases with different jet-to-crossflow pressure ratio, and we observe that the Mach numbers upstream of the leading edge of 
the strut for Cases 9 and 10 are below 1.0. The isolator operates in the subsonic condition. At the same time, it is clearly observed that the subsonic region becomes larger with the increase of the jet-to-crossflow pressure ratio.

Fig.12 represents the mixing efficiency comparison for cases with different jet-to-crossflow pressure ratios, and it is observed that the mixing efficiency decreases with the increase of the jet-to-crossflow pressure ratio. This conclusion is consistent with that observed in the traditional transverse injection flow field, see Ref. [35].

\section{Conclusions}

In the current study, the ram-to-scram mode transition process has been investigated numerically, and the influences of the inlet boundary conditions at the entrance of the isolator, the injection strategy, and the jet-to-crossflow pressure ratio on the mode transition have been evaluated in detail. We have come to the following conclusions:

- The inlet boundary conditions at the entrance of the isolator and the jet-to-crossflow pressure ratio both have a large impact on the ram-to-scram mode transition, and the effect of the injection strategy can be neglected in this paper. The engine would operate in the ramjet mode when the freestream Mach number is lower, and it would be converted into scramjet mode with the increase of the flight velocity.

- The separation zone would expand upstream with the increase of the jet-to-crossflow pressure ratio, and this is induced by the movement of the shock wave train in the isolator. The subsonic velocity region becomes larger with the increase of the jet-to-crossflow pressure ratio as well, and the engine would operate in the ramjet mode completely when the jet-to-crossflow pressure ratio is large enough, namely 10.0 and 15.0 in this paper.

\section{Acknowledgements}

The authors would like to express their thanks for the support from the National Science Foundation of China 
(No. 11502291) and a fund for owner of Outstanding Doctoral Dissertation from the Ministry of Education of China (No.201460). Also, the authors thank the anonymous reviewers for some very critical and constructive recommendations on this article.

\section{References}

1. Huang W, Yan L, Tan J G. Survey on the mode transition technique in combined cycle propulsion systems. Aerospace Science and Technology, 2014, 39: 685-691

2. Micka D J, Driscoll J F. Combustion characteristics of a dual-mode scramjet combustor with cavity flameholder. Proceedings of the Combustion Institute, 2009, 32: 2397-2404

3. Dessornes O, Scherrer D. Tests of the JAPHAR dual mode ramjet engine. Aerospace Science and Technology, 2005, 9: 211-221

4. Weber R J, Mackay J S. An analysis of ramjet engines using supersonic combustion. NASA TN 4386, 1958

5. Huang W, Ma L, Pourkashanian M, Ingham D B, Luo S B, Liu J, Wang Z G. Flow-field analysis of a typical hydrogen-fueled dual-mode scramjet combustor. Journal of Aerospace Engineering, 2012, 25: $336-346$

6. Cao R F, Chang J T, Bao W, Guo M L, Qin J, Yu D R, Wang Z Q. Analysis of combustion mode and operating route for hydrogen fueled scramjet engine. International Journal of Hydrogen Energy, in press, doi: 10.1016/j.ijhydene.2013.02.135

7. Kobayashi K, Tomioka S, Kato K, Murakami A, Kudo K. Performance of a dual-mode combustor with multistaged fuel injection. Journal of Propulsion and Power, 2006, 22(3): 518-526

8. Zhang Y, Chen B, Liu G, Wei B X, Xu X. Influencing factors on the mode transition in a dual-mode scramjet. Acta Astronautica, in press, doi: 10.1016/j.actaastro.2014.06.006

9. Cui T, Tang S L, Zhang C, Yu D R. Hysteresis phenomenon of mode transition in ramjet engines and its 
topological rule. Journal of Propulsion and Power, 2012, 28(6): 1277-1284

10. Bao W, Yang Q C, Chang J T, Zong Y H, Hu J C. Dynamic characteristics of combustion mode transitions in a strut-based scramjet combustor model. Journal of Propulsion and Power, 2013, 29(5): 1244-1248

11. Fotia M L, Driscoll J F. Ram-scram transition and flame/shock-train interactions in a model scramjet experiment. Journal of Propulsion and Power, 2013, 29(1): 261-273

12. Huang W, Wang Z G, Luo S B, Liu J. Parametric effects on the combustion flow field of a typical strut-based scramjet combustor. Chinese Science Bulletin, 2011, 56(35): 3871-3877

13. Goyne C P, McDaniel Jr. J C, Krauss R H, Whitehurst W B. Test gas vitiation effects in a dual-mode scramjet combustor. Journal of Propulsion and Power, 2007, 23(3): 559-565

14. Rockwell Jr. R D, Goyne C P, Haw W, Krauss R H, McDaniel J C, Trefny C J. Experimental study of test-medium vitiation effects on dual-mode scramjet performance. Journal of Propulsion and Power, 2011, 27(5): 1135-1142

15. Turner J C, Smart M K. Mode change characteristics of a three-dimensional scramjet at Mach 8. Journal of Propulsion and Power, 2013, 29(4): 982-990

16. Xiao B G, Xing J W, Tian Y, Wang X Y. Experimental and numerical investigations of combustion mode transition in a direct-connect scramjet combustor. Aerospace Science and Technology, in press, doi: 10.1016/j.ast.2015.08.001

17. Torrez S M, Dalle D J, Driscoll J F. New method for computing performance of choked reacting flows and ram-to-scram transition. Journal of Propulsion and Power, 2013, 29(2): 433-445

18. Milligan R T, Eklund D R, Wolff J M, Gruber M, Mathur T. Dual-mode scramjet combustor: numerical analysis of two flowpaths. Journal of Propulsion and Power, 2011, 27(6): 1317-1319

19. Abdel-Salam T M, Carson R A. Three-dimensional numerical study of a dual-mode scramjet combustor. 37th AIAA Thermophysics Conference, Portland, Oregon, AIAA Paper 2004-2384, 2004 
20. Oevermann M. Numerical investigation of turbulent hydrogen combustion in a SCRAMJET using flamelet modeling. Aerospace Science and Technology, 2000, 4: 463-480

21. Huang W, Wang Z G, Pourkashanian M, Ma L, Ingham D B, Luo S B, Lei J, Liu J. Numerical investigation on the shock wave transition in a three-dimensional scramjet isolator. Acta Astronautica, 2011, 68: $1669-1675$

22. Huang W, Liu W D, Li S B, Xia Z X, Liu J, Wang Z G. Influences of the turbulence model and the slot width on the transverse slot injection flow field in supersonic flows. Acta Astronautica, 2012, 73: 1-9

23. Sullins G A. Demonstration of mode transition in a scramjet combustor. Journal of Propulsion and Power, 1993, 9(4): 515-520

24. Fluent Inc. Fluent 6.3 user's guide, Lebanon, NH, Fluent Inc, 2006

25. Desikan S L N, Saravanan R, Subramanian S, Sivararamakrishnan A E, Pandian S. Investigation of supersonic jet interaction with hypersonic cross flow. Journal of Fluids Engineering, 2015, 137: 101101

26. Erdem E, Kontis K. Numerical and experimental investigation of transverse injection flows. Shock Waves, 2010, 20: 103-118

27. Jachimowski C J. An analytic study of the hydrogen-air reaction mechanism with application to scramjet combustor. NASA Tech. Pap. 2781, 1988

28. Huang W, Wang Z G, Li S B, Liu W D. Influences of $\mathrm{H}_{2} \mathrm{O}$ mass fraction and chemical kinetics mechanism on the turbulent diffusion combustion of $\mathrm{H}_{2}-\mathrm{O}_{2}$ in supersonic flows. Acta Astronautica, 2012, 76: 51-59

29. Huang W, Li S B, Yan L, Wang Z G. Performance evaluation and parametric analysis on cantilevered ramp injector in supersonic flows. Acta Astronautica, 2013, 84: 141-152

30. Marshall C B, Kurkov A P. Analytical and experimental study of supersonic combustion of hydrogen in a vitiated air stream. NASA TM X 2828, 1973

31. Segal C. The scramjet engine processes and characteristics. Cambridge University Press, 2009 
32. Huang W, Wang Z G, Jin L, Liu J. Effect of cavity location on combustion flow field of integrated hypersonic vehicle in near space. Journal of Visualization, 2011, 14: 339-351

33. Northam G B, Anderson G Y. Review of NASA/Langley basic research on supersonic combustion. AIAA Paper 86-0159, 1986

34. Huang W, Jin L, Yan L, Tan J G. Influence of jet-to-crossflow pressure ratio on nonreacting and reacting processes in a scramjet combustor with backward-facing steps. International Journal of Hydrogen Energy, 2014, 39: 21242-21250

35. Huang W. Design exploration of three-dimensional transverse jet in a supersonic crossflow based on data mining and multi-objective design optimization approaches. International Journal of Hydrogen Energy, 2014, 39: 3914-3925 


\section{Figure captions}

Fig.1 Schematic diagram of the strut-based dual-mode scramjet combustor (unit: $\mathrm{mm}$ ).

Fig.2 Close-up view for the grid system around the strut and steps.

Fig.3 Hydrogen mole fraction profile comparison at the exit of the combustor under the combustion condition.

Fig.4 Mach number contour comparison for cases with different inlet boundary conditions.

Fig.5 Mach number profile comparison for cases with different inlet boundary conditions.

Fig.6 Mixing efficiency comparison for cases with different inlet boundary conditions.

Fig.7 Mach number contour comparison for cases with different injection schemes.

Fig.8 Mach number profile comparison for cases with different injection schemes.

Fig.9 Mixing efficiency comparison for cases with different injection schemes.

Fig.10 Mach number contour comparison for cases with different jet-to-crossflow pressure ratios.

Fig.11 Mach number profile comparison for cases with different jet-to-crossflow pressure ratio.

Fig.12 Mixing efficiency comparison for cases with different jet-to-crossflow pressure ratios. 


\section{Table captions}

Table.1 Boundary conditions for the cases employed in the current study.

Table.2 Rate parameters for the different $\mathrm{H}_{2}$-air mechanisms.

Table.3 Arrangement of injection scheme in the current study.

Table.4 Jet-to-crossflow pressure ratios for Cases 8-10. 


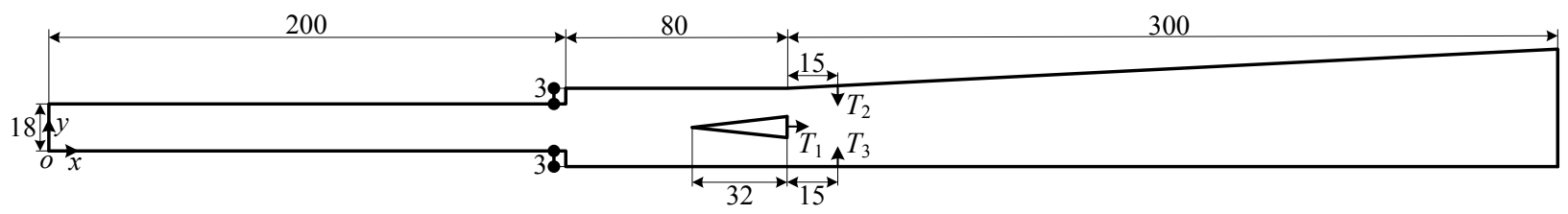

Fig.1 Schematic diagram of the strut-based dual-mode scramjet combustor (unit: $\mathrm{mm}$ ).

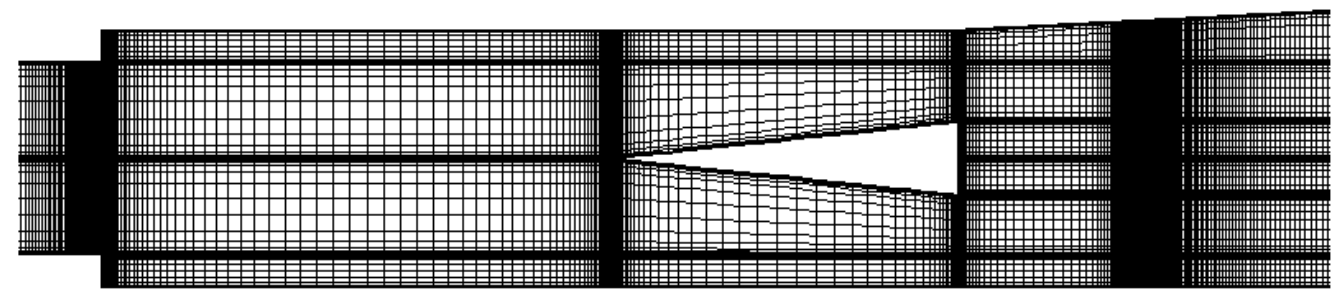

Fig.2 Close-up view for the grid system around the strut and steps. 


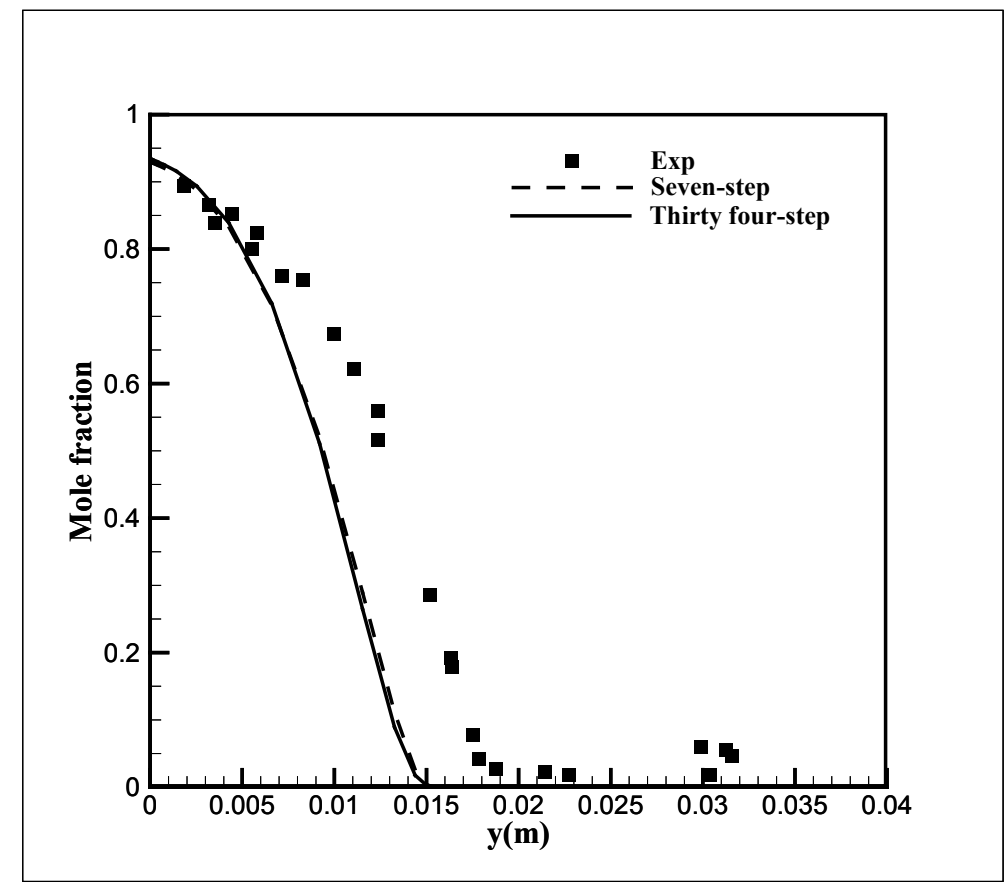

Fig.3 Hydrogen mole fraction profile comparison at the exit of the combustor under the combustion condition. 


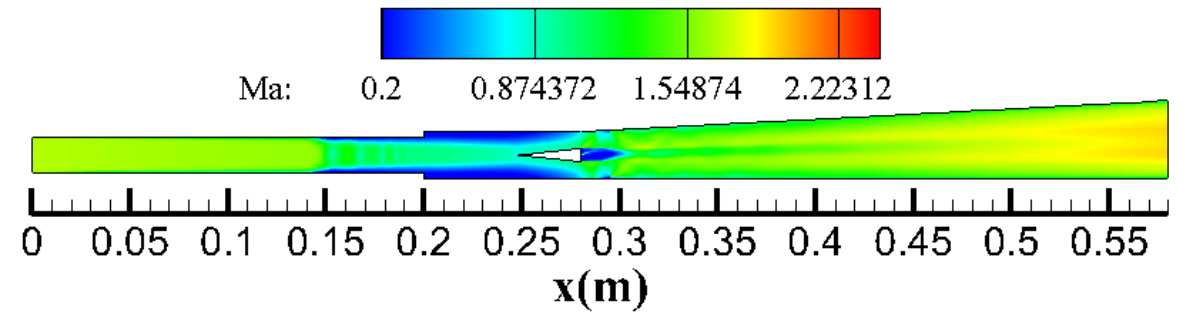

(a) Case 1

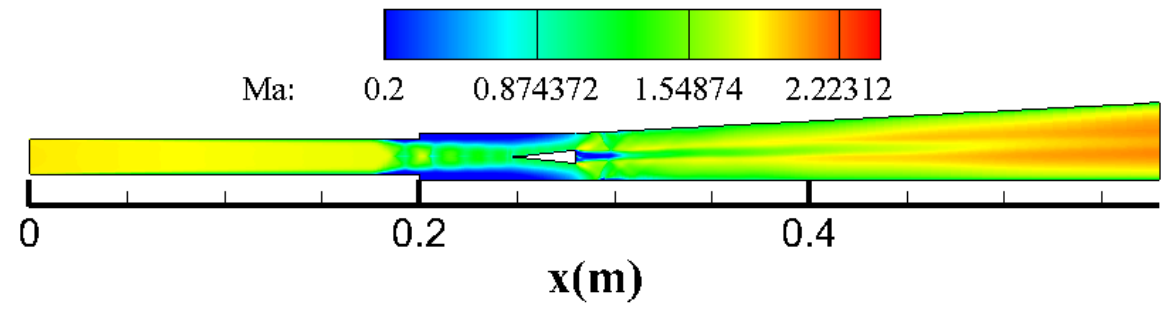

(b) Case 2

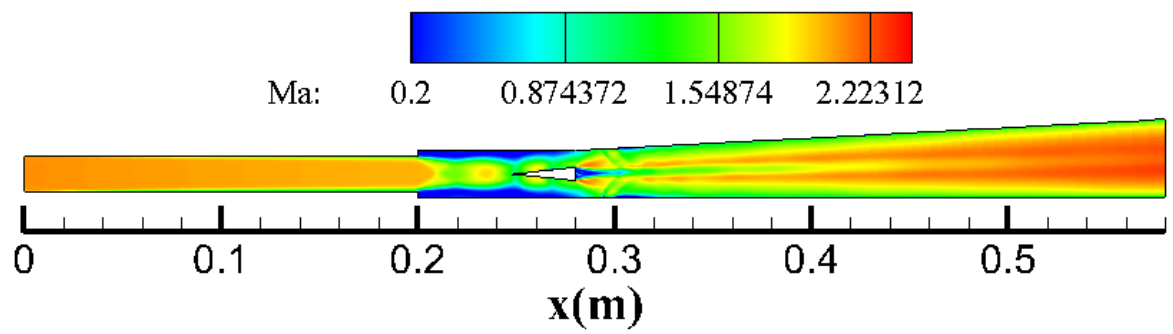

(c) Case 3

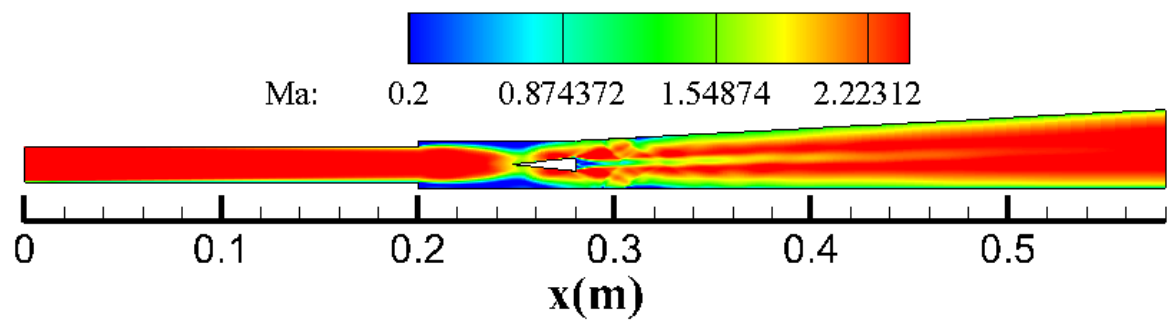

(d) Case 4

Fig.4 Mach number contour comparison for cases with different inlet boundary conditions. 


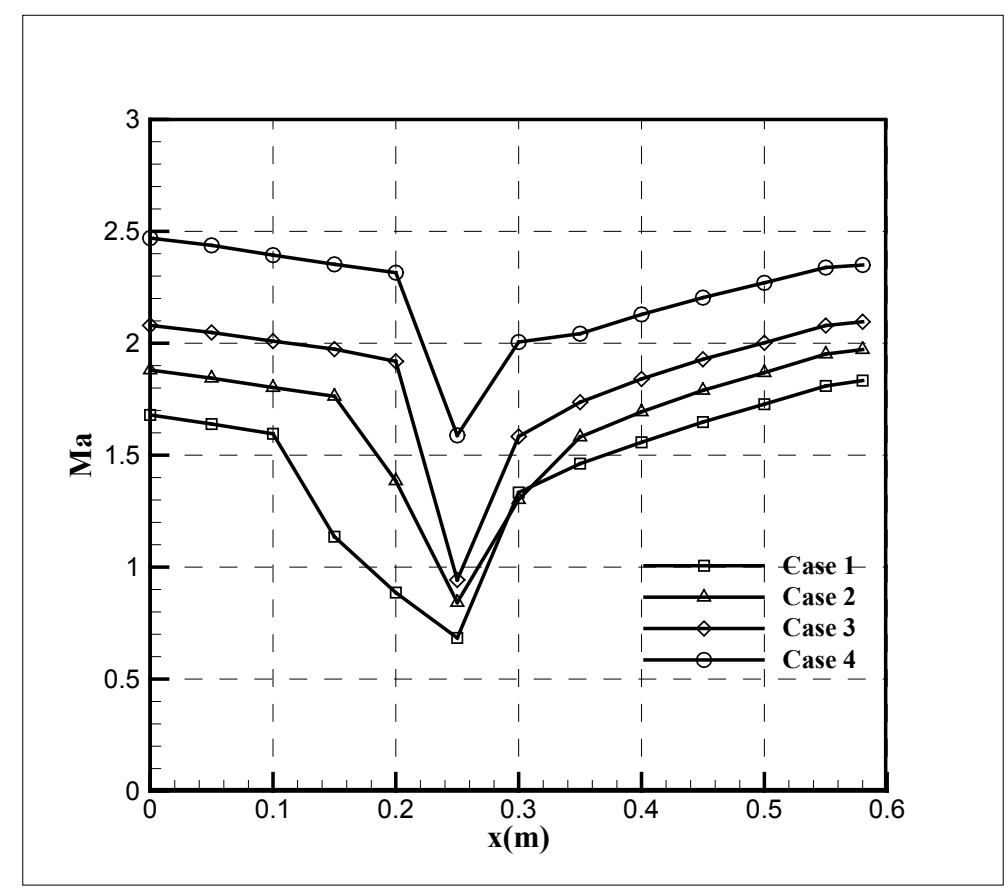

Fig.5 Mach number profile comparison for cases with different inlet boundary conditions.

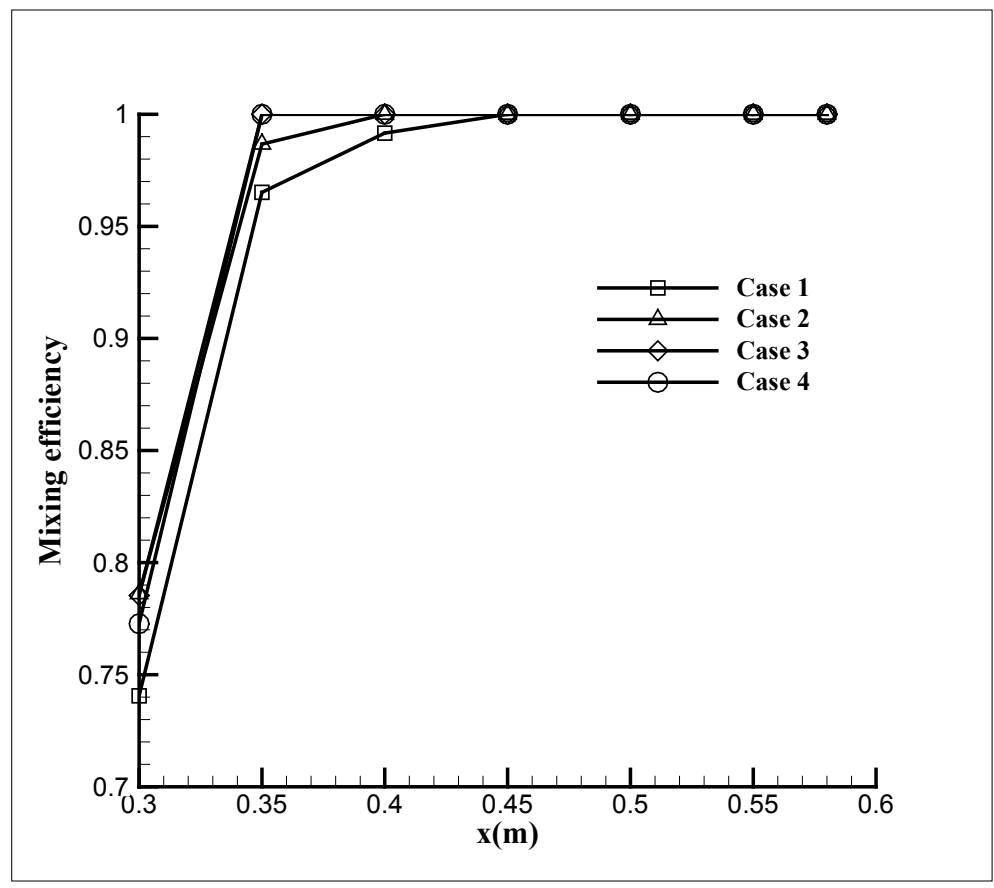

Fig.6 Mixing efficiency comparison for cases with different inlet boundary conditions. 


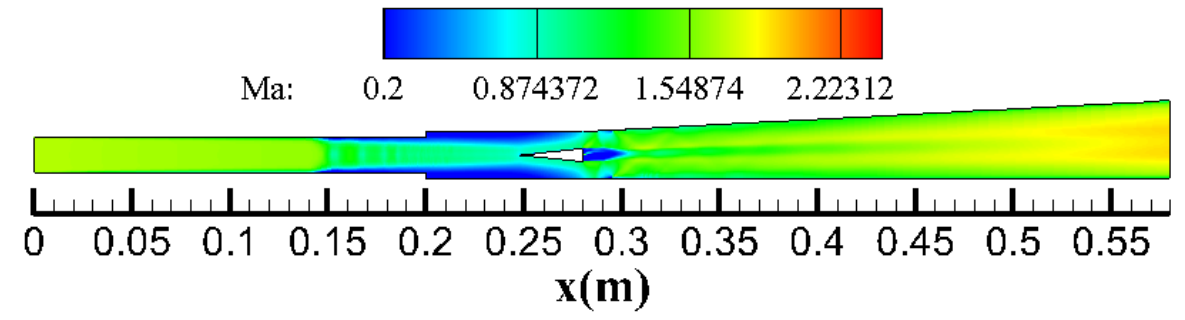

(a) Case 1

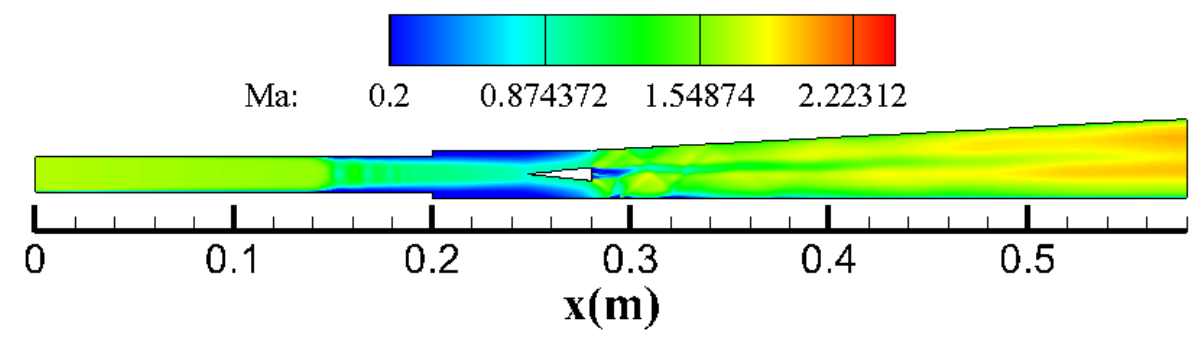

(b) Case 5

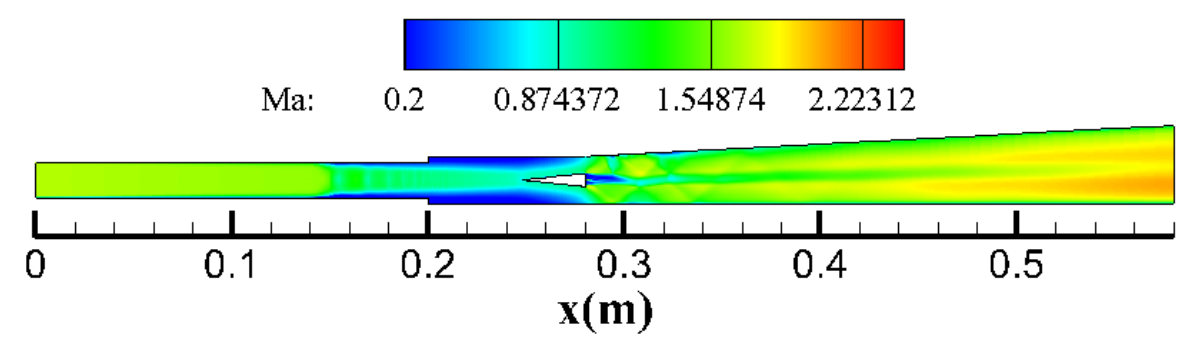

(c) Case 6

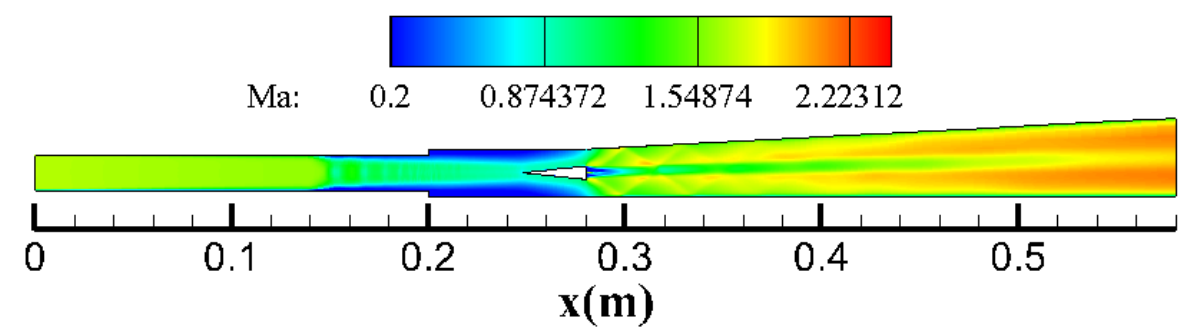

(d) Case 7

Fig.7 Mach number contour comparison for cases with different injection schemes. 


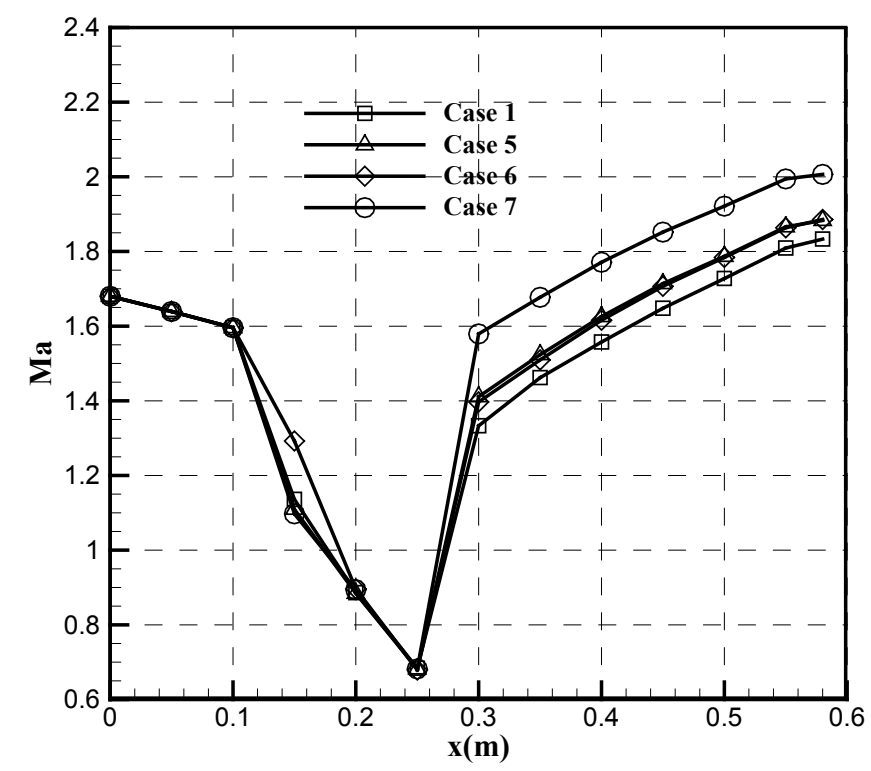

Fig.8 Mach number profile comparison for cases with different injection schemes.

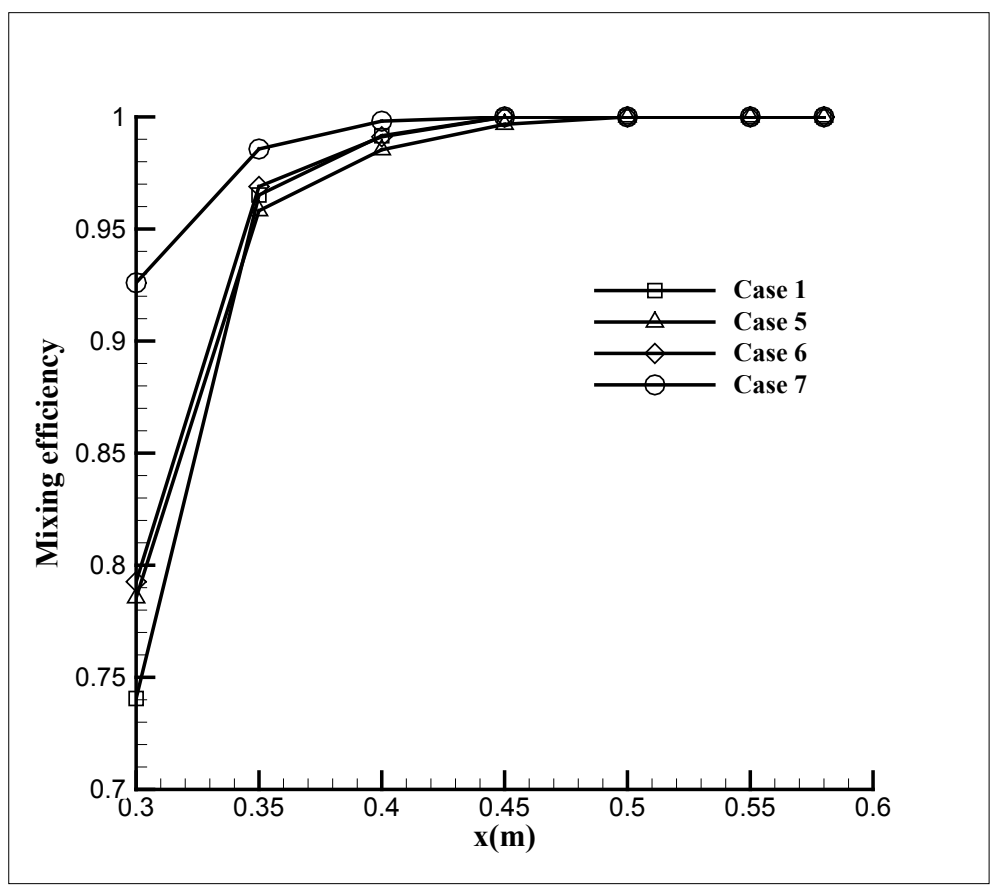

Fig.9 Mixing efficiency comparison for cases with different injection schemes. 


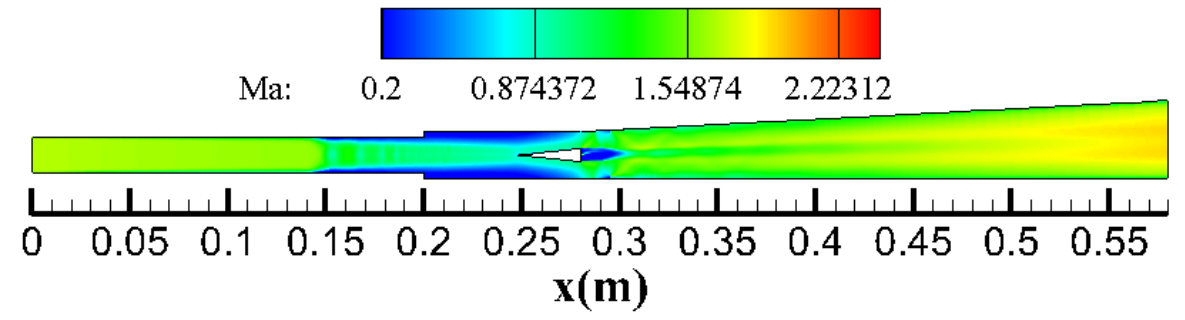

(a) Case 1

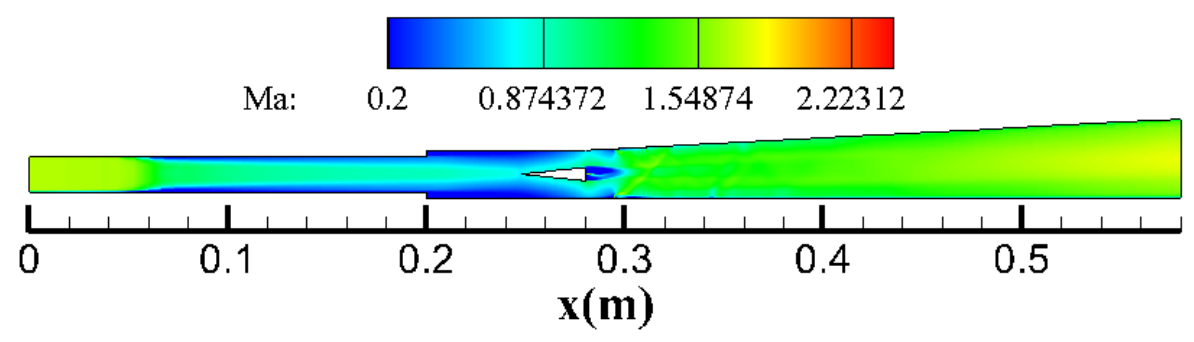

(b) Case 8

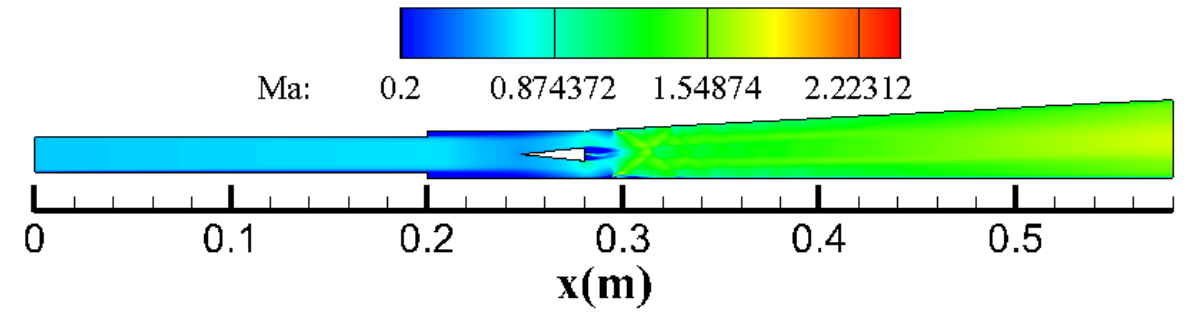

(c) Case 9

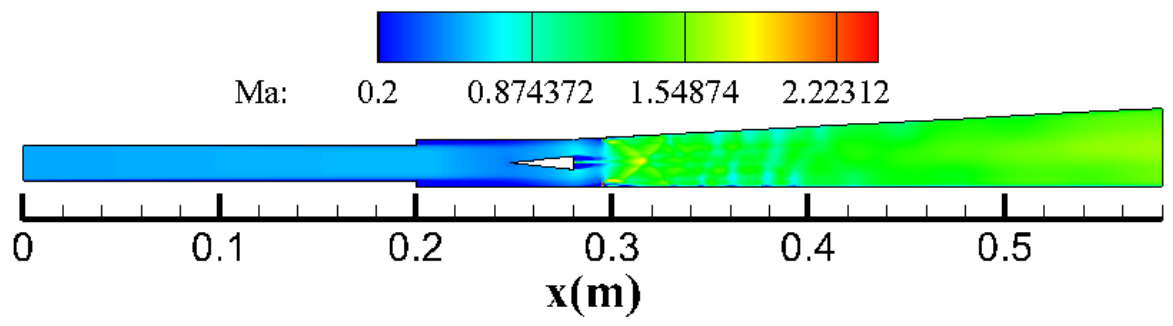

(d) Case 10

Fig.10 Mach number contour comparison for cases with different jet-to-crossflow pressure ratios. 


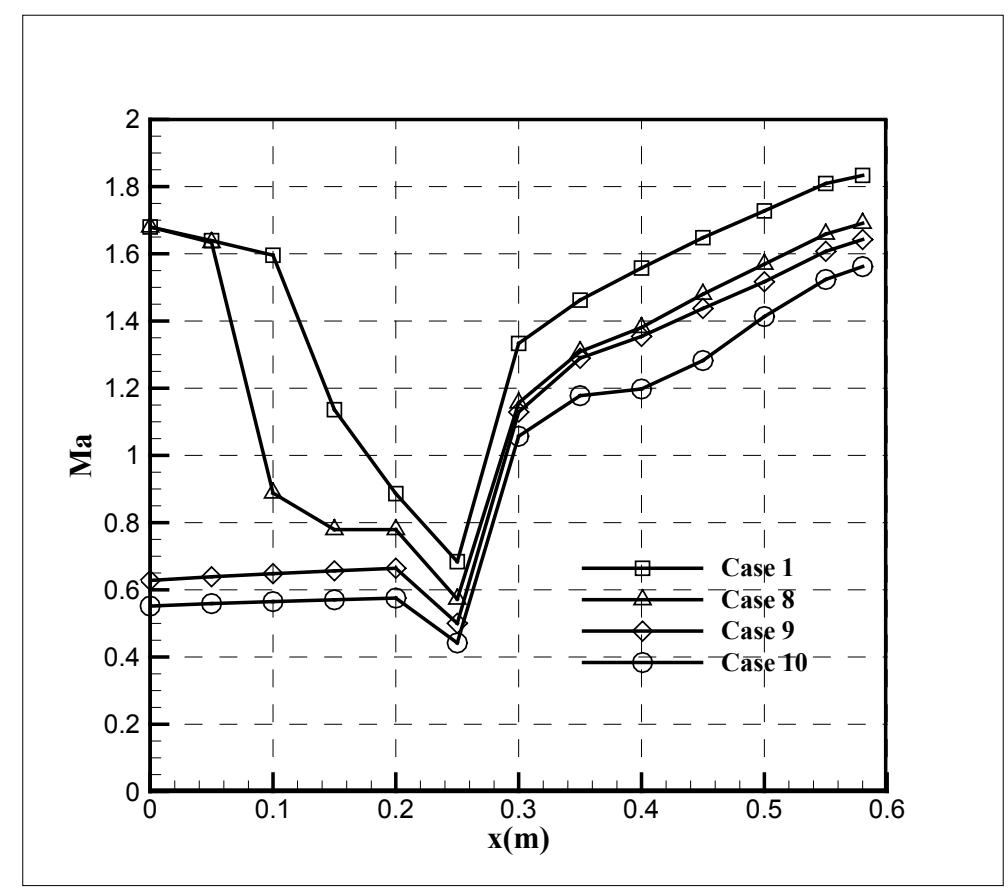

Fig.11 Mach number profile comparison for cases with different jet-to-crossflow pressure ratio.

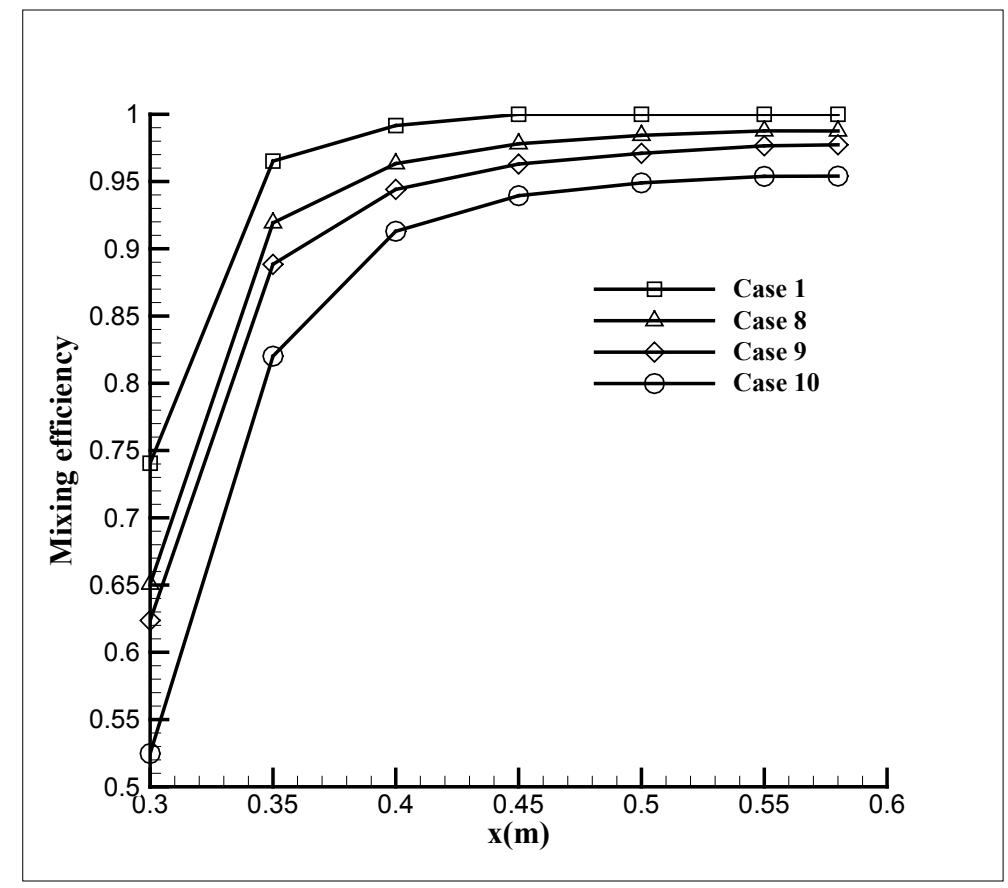

Fig.12 Mixing efficiency comparison for cases with different jet-to-crossflow pressure ratios. 
Table.1 Boundary conditions for the cases employed in the current study.

\begin{tabular}{|c|c|c|c|c|}
\hline & Case 1 & Case 2 & Case 3 & Case 4 \\
\hline$M_{\infty}$ & 4 & 5 & 6 & 7 \\
\hline$H(\mathrm{~km})$ & 20 & 23 & 25 & 27 \\
\hline$M_{\mathrm{i}}$ & 1.7 & 1.9 & 2.1 & 2.5 \\
\hline$T_{\mathrm{i}}(\mathrm{K})$ & 900 & 1300 & 1810 & 2400 \\
\hline$P_{\mathrm{i}}(\mathrm{atm})$ & 7.2 & 14.8 & 29.3 & 48.7 \\
\hline
\end{tabular}


Table.2 Rate parameters for the different $\mathrm{H}_{2}$-air mechanisms.

\begin{tabular}{|c|c|c|c|c|c|}
\hline Mechanism & No. & Reaction & $A(\mathrm{~m}, \mathrm{~kg}, \mathrm{~mol}, \mathrm{~s}, \mathrm{~K})$ & $N$ & $T_{\mathrm{a}}(\mathrm{K})$ \\
\hline \multirow[t]{7}{*}{ Seven-step[27] } & 1 & $\mathrm{H}+\mathrm{OH}+\mathrm{M} \rightarrow \mathrm{H}_{2} \mathrm{O}+\mathrm{M}$ & $2.21 \times 10^{22}$ & -2.0 & 0.0 \\
\hline & 2 & $\mathrm{H}+\mathrm{H}+\mathrm{M} \rightarrow \mathrm{H}_{2}+\mathrm{M}$ & $7.30 \times 10^{17}$ & -1.0 & 0.0 \\
\hline & 3 & $\mathrm{H} 2+\mathrm{O} 2 \rightarrow \mathrm{OH}+\mathrm{OH}$ & $1.70 \times 10^{13}$ & 0.0 & 48,000 \\
\hline & 4 & $\mathrm{H}+\mathrm{O}_{2} \rightarrow \mathrm{OH}+\mathrm{O}$ & $1.20 \times 10^{17}$ & -0.9 & 16,800 \\
\hline & 5 & $\mathrm{OH}+\mathrm{H}_{2} \rightarrow \mathrm{H}_{2} \mathrm{O}+\mathrm{H}$ & $2.20 \times 10^{13}$ & 0.0 & 5,150 \\
\hline & 6 & $\mathrm{O}+\mathrm{H}_{2} \rightarrow \mathrm{OH}+\mathrm{H}$ & $5.06 \times 10^{4}$ & 2.7 & 6,268 \\
\hline & 7 & $\mathrm{OH}+\mathrm{OH} \rightarrow \mathrm{H}_{2} \mathrm{O}+\mathrm{O}$ & $6.30 \times 10^{12}$ & 0.0 & 1,090 \\
\hline \multirow[t]{34}{*}{ Thirty four-step } & 1 & $\mathrm{H}+\mathrm{O}_{2} \rightarrow \mathrm{O}+\mathrm{OH}$ & $1.86 \times 10^{14}$ & 0.0 & 16,790 \\
\hline & 2 & $\mathrm{O}+\mathrm{OH} \rightarrow \mathrm{H}+\mathrm{O}_{2}$ & $1.48 \times 10^{13}$ & 0.0 & 680 \\
\hline & 3 & $\mathrm{H}_{2}+\mathrm{O} \rightarrow \mathrm{H}+\mathrm{OH}$ & $1.82 \times 10^{10}$ & 1.0 & 8,900 \\
\hline & 4 & $\mathrm{H}+\mathrm{OH} \rightarrow \mathrm{H}_{2}+\mathrm{O}$ & $8.32 \times 10^{9}$ & 1.0 & 6,950 \\
\hline & 5 & $\mathrm{H}_{2} \mathrm{O}+\mathrm{O} \rightarrow \mathrm{OH}+\mathrm{OH}$ & $3.39 \times 10^{13}$ & 0.0 & 18,350 \\
\hline & 6 & $\mathrm{OH}+\mathrm{OH} \rightarrow \mathrm{H}_{2} \mathrm{O}+\mathrm{O}$ & $3.16 \times 10^{12}$ & 0.0 & 1100 \\
\hline & 7 & $\mathrm{H}_{2} \mathrm{O}+\mathrm{H} \rightarrow \mathrm{H}_{2}+\mathrm{OH}$ & $9.55 \times 10^{13}$ & 0.0 & 20,300 \\
\hline & 8 & $\mathrm{H}_{2}+\mathrm{OH} \rightarrow \mathrm{H}_{2} \mathrm{O}+\mathrm{H}$ & $2.19 \times 10^{13}$ & 0.0 & 5,150 \\
\hline & 9 & $\mathrm{H}_{2} \mathrm{O}_{2}+\mathrm{OH} \rightarrow \mathrm{H}_{2} \mathrm{O}+\mathrm{HO}_{2}$ & $1.00 \times 10^{13}$ & 0.0 & 1,800 \\
\hline & 10 & $\mathrm{H}_{2} \mathrm{O}+\mathrm{HO}_{2} \rightarrow \mathrm{H}_{2} \mathrm{O}_{2}+\mathrm{OH}$ & $2.82 \times 10^{13}$ & 0.0 & 32,790 \\
\hline & 11 & $\mathrm{HO}_{2}+\mathrm{O} \rightarrow \mathrm{OH}+\mathrm{O}_{2}$ & $5.01 \times 10^{13}$ & 0.0 & 1,000 \\
\hline & 12 & $\mathrm{OH}+\mathrm{O}_{2} \rightarrow \mathrm{HO}_{2}+\mathrm{O}$ & $6.46 \times 10^{13}$ & 0.0 & 56,160 \\
\hline & 13 & $\mathrm{HO} 2+\mathrm{H} \rightarrow \mathrm{OH}+\mathrm{OH}$ & $2.51 \times 10^{14}$ & 0.0 & 1,900 \\
\hline & 14 & $\mathrm{OH}+\mathrm{OH} \rightarrow \mathrm{HO}_{2}+\mathrm{H}$ & $1.20 \times 10^{13}$ & 0.0 & 40,100 \\
\hline & 15 & $\mathrm{HO}_{2}+\mathrm{H} \rightarrow \mathrm{H}_{2}+\mathrm{O}_{2}$ & $2.51 \times 10^{13}$ & 0.0 & 700 \\
\hline & 16 & $\mathrm{H}_{2}+\mathrm{O}_{2} \rightarrow \mathrm{HO}_{2}+\mathrm{H}$ & $5.50 \times 10^{13}$ & 0.0 & 57,800 \\
\hline & 17 & $\mathrm{HO}_{2}+\mathrm{OH} \rightarrow \mathrm{H}_{2} \mathrm{O}+\mathrm{O}_{2}$ & $5.01 \times 10^{13}$ & 0.0 & 1,000 \\
\hline & 18 & $\mathrm{H}_{2} \mathrm{O}+\mathrm{O}_{2} \rightarrow \mathrm{HO}_{2}+\mathrm{OH}$ & $6.31 \times 10^{14}$ & 0.0 & 73,860 \\
\hline & 19 & $\mathrm{H}_{2} \mathrm{O}_{2}+\mathrm{O}_{2} \rightarrow \mathrm{HO}_{2}+\mathrm{HO}_{2}$ & $3.98 \times 10^{13}$ & 0.0 & 42,640 \\
\hline & 20 & $\mathrm{HO}_{2}+\mathrm{HO}_{2} \rightarrow \mathrm{H}_{2} \mathrm{O}_{2}+\mathrm{O}_{2}$ & $1.00 \times 10^{13}$ & 0.0 & 1,000 \\
\hline & 21 & $\mathrm{H}_{2} \mathrm{O}_{2}+\mathrm{H} \rightarrow \mathrm{HO}_{2}+\mathrm{H}_{2}$ & $1.70 \times 10^{12}$ & 0.0 & 3,750 \\
\hline & 22 & $\mathrm{HO}_{2}+\mathrm{H}_{2} \rightarrow \mathrm{H}_{2} \mathrm{O}_{2}+\mathrm{H}$ & $7.24 \times 10^{11}$ & 0.0 & 18,700 \\
\hline & 23 & $\mathrm{H}_{2} \mathrm{O}+\mathrm{M} \rightarrow \mathrm{H}+\mathrm{OH}+\mathrm{M}$ & $2.19 \times 10^{16}$ & 0.0 & 105,000 \\
\hline & 24 & $\mathrm{H}+\mathrm{OH}+\mathrm{M} \rightarrow \mathrm{H}_{2} \mathrm{O}+\mathrm{M}$ & $1.41 \times 10^{23}$ & -2.0 & 0 \\
\hline & 25 & $\mathrm{H}+\mathrm{O}_{2}+\mathrm{M} \rightarrow \mathrm{HO}_{2}+\mathrm{M}$ & $1.66 \times 10^{15}$ & 0.0 & $-1,000$ \\
\hline & 26 & $\mathrm{HO}_{2}+\mathrm{M} \rightarrow \mathrm{H}+\mathrm{O}_{2}+\mathrm{M}$ & $2.29 \times 10^{15}$ & 0.0 & 45,900 \\
\hline & 27 & $\mathrm{H}_{2} \mathrm{O}_{2}+\mathrm{M} \rightarrow \mathrm{OH}+\mathrm{OH}+\mathrm{M}$ & $1.20 \times 10^{17}$ & 0.0 & 45,500 \\
\hline & 28 & $\mathrm{OH}+\mathrm{OH}+\mathrm{M} \rightarrow \mathrm{H}_{2} \mathrm{O}_{2}+\mathrm{M}$ & $9.12 \times 10^{14}$ & 0.0 & 5,070 \\
\hline & 29 & $\mathrm{O}+\mathrm{H}+\mathrm{M} \rightarrow \mathrm{OH}+\mathrm{M}$ & $1.00 \times 10^{16}$ & 0.0 & 0 \\
\hline & 30 & $\mathrm{OH}+\mathrm{M} \rightarrow \mathrm{O}+\mathrm{H}+\mathrm{M}$ & $7.94 \times 10^{19}$ & -1.0 & 103,720 \\
\hline & 31 & $\mathrm{O}_{2}+\mathrm{M} \rightarrow \mathrm{O}+\mathrm{O}+\mathrm{M}$ & $5.13 \times 10^{15}$ & 0.0 & 115,000 \\
\hline & 32 & $\mathrm{O}+\mathrm{O}+\mathrm{M} \rightarrow \mathrm{O}_{2}+\mathrm{M}$ & $4.68 \times 10^{15}$ & -0.3 & 0 \\
\hline & 33 & $\mathrm{H}_{2}+\mathrm{M} \rightarrow \mathrm{H}+\mathrm{H}+\mathrm{M}$ & $2.19 \times 10^{14}$ & 0.0 & 96,000 \\
\hline & 34 & $\mathrm{H}+\mathrm{H}+\mathrm{M} \rightarrow \mathrm{H}_{2}+\mathrm{M}$ & $3.02 \times 10^{15}$ & 0.0 & 0 \\
\hline
\end{tabular}

Note: $[\mathrm{M}]=2.5\left[\mathrm{H}_{2}\right]+16.0\left[\mathrm{H}_{2} \mathrm{O}\right]+1.0[\mathrm{OTHER}]$ and $[\mathrm{M}]=0.4\left[\mathrm{O}_{2}\right]+6.5\left[\mathrm{H}_{2} \mathrm{O}\right]+0.0\left[\mathrm{~N}_{2}\right]+1.0[\mathrm{OTHER}]$ for seven-step and thirty four-step H2-air mechanisms, respectively. 
Table.3 Arrangement of injection scheme in the current study.

\begin{tabular}{|l|c|c|c|}
\hline & Case 5 & Case 6 & Case 7 \\
\hline Injection scheme & $T_{1}, T_{3}$ & $T_{1}, T_{2}$ & $T_{1}$ \\
\hline & & & \\
\hline
\end{tabular}

Table.4 Jet-to-crossflow pressure ratios for Cases 8-10.

\begin{tabular}{|l|c|c|c|}
\hline & Case 8 & Case 9 & Case 10 \\
\hline Jet-to-crossflow pressure ratio & 7 & 10 & 15 \\
\hline
\end{tabular}

